\title{
FUZZY INFERENCE SYSTEM MAMDANI DAN THE MEAN ABSOLUTE PERCENTAGE ERROR (MAPE) UNTUK PREDIKSI PERMINTAAN DOMPET PULSA PADA XL AXIATA DEPOK
}

\author{
Mochammad Bagoes Satria Junianto \\ Fakultas Teknik, Universitas Pamulang \\ Email :dosen00849@unpam.ac.id
}

\begin{abstract}
ABSTRAK
Kemajuan perkembangan teknologi informasi pada era globalisasi sekarang ini sangat pesat, hal ini menuntut setiap perusahaan untuk dapat saling bersaing dalam dunia bisnis yang dinamis dan penuh persaingan. Pada proses manjaemen permintaan dompet pulsa di XL Axiata cabang Depok memerlukan peramalan yang cukup matang agar dompet pulsa yang diminta kepada pusat tidak berlebihan atau tidak terlalu sedikit untuk menjaga kestabilan antara penjualan, persediaan dan jumlah permintaan. Untuk dapat melakukan peramalan yang lebih akurat, maka diperlukan suatu metode yang dapat menghitung ketidakpastian yang terjadi, dalam hal ini metode yang digunakan adalah dengan menggunakan Fuzzy inference system metode Mamdani untuk meramalkan jumlah permintaan dompet pulsa berdasarkan jumlah penjualan dan persediaan. Dengan 12 sample data untuk masing-masing sistem satuam yang digunakan hasil yang didapatkan yaitu dengan menggunakan Fuzzy inference system metode mamdani MAPE yang didapat sebesar 18,56\% untuk Dompul XL 5k, 5,38\% untuk Dompul XL 10k dan 14,2\% untuk Dompul XL Rupiah.
\end{abstract}

Kata Kunci : FIS Mamdani, MAPE, Dompul XL

\section{PENDAHULUAN}

PT XL axiata, Tbk selaku salah satu penyedia layanan telekomunikasi yang sangat besar di indonesia yang mempunyai trademark XL axiata mempunyai produk dompet pulsa. Dompet Pulsa (DOMPUL) adalah salah satu bentuk program yang secara resmi dikeluarkan oleh XL Axiata dalam menunjang pelaksanaan pengisian pulsa elektrik XL kepada pelanggannya. Dompet Pulsa ini menggunakan chip tersendiri untuk melakukan transaksi pembelian pulsa elektrik yang bisa di miliki setiap Retail Outlet dengan cara membelinya langsung ke dealer resmi XL Axiata yang ada disetiap kota masing-masing atau memlalui sales representatif yang mereka punya. Dompet Pulsa ini menggunakan 2 macam sistem stok yaitu sitem satuan units untuk $5 \mathrm{k}$ dan $10 \mathrm{k}$ serta sistem rupiah untuk $25 \mathrm{k}, 50 \mathrm{k}$ dan $100 \mathrm{k}$. Permasalahan yang terjadi pada dealer XL kota depok adalah permintaan stok bulanan yang masih menggunakan prediksi manual. Kelemahan dari prediksi manual ini sendiri adalah bila permintaan kurang maka persediaan tidak akan cukup untuk 1 bulan dan mengakibatkan hilangnya kepercayaan konsmen. Dalam penelitian ini akan coba dilakukan penerapan fuzzy inference system (FIS) metode mamdani terhadap prediksi permintaan stok dompet pulsa baik berupa unit maupun rupiah pada dealer XL Axiata cabang Depok dengan mepertimbangkan persediaan maupun tingkat penjualan.

\section{METODE PENELITIAN}

Penelitiaan ini dilakukan di PT XL Axiata Tbk cabang Depok dengan meneliti objek produk Dompet pulsa baik satuan unit $5 \mathrm{k}$ dan $10 \mathrm{k}$ maupun Rupiah, dengan mempertimbangangkan beberapa variabel diantaranya penjualan pembelian dan stok. Data yang diolah adalah data primer yang didapatkan langsung dari perusahaan dan diolah dengan menggunakan

Fuzzy Inference System Mamdani.

Untuk mendapatkan output, diperlukan 4 tahapan : (Kusumadewi, 2013)

a) Pembentukan himpunan fuzzy.

Pada metode mamdani, baik variabel input maupun variabel output dibagi menjadi satu atau lebih himpunan fuzzy.

b) Aplikasi fungsi implikasi. Pada metode Mamdani, fungsi implikasi yang digunakan adalah Min

c) Komposisi aturan.

Tidak seperti penalaran monoton, apabila sistem terdiri dari beberapa aturan, maka 
ISSN 2541-1004

inferensi diperoleh dari kumpulan dan korelasi antar aturan. Ada 3 metode yang digunakan dalam melakukan inferensi sistem fuzzy, yaitu : max, additive, dan probabilistic OR (probor)

d) Penegasan (defuzzy).

Input dari poses defuzzyfikasi adalah suatu himpunan fuzzy yang diperoleh dari komposisi aturan-aturan fuzzy, sedangkan output yang dihasilkan merupakan suatu bilangan pada domain himpunan fuzzy tersebut. Sehingga jika deberikan suatu himpunan fuzzy dalam range tertentu, maka harus dapat diambil suatu nilai crisp tertentu sebagai output.

\section{The Mean Absolute Percentage Error (MAPE) \\ $M A P E$ dihitung dengan menggunakan} kesalahan absolute pada tiap periode dibagi dengan nilai observasi yang nyata untuk periode itu . Kemudian merata-rata kesalahan percentase absolut tersebut (Render, 2015). Pendekatan ini berguna ketika ukuran atau besar variabel ramalan itu penting dalam mengevaluasi ketepatan ramalan. MAPE mengindikasi seberapa besar kesalahan dalam meramal yang dibandingkan nilai nyata dalam deret. Metode MAPE dapat dihitung dengan rumus berikut :

$$
M A P E=\frac{1}{n} \sum_{t=1}^{n} \frac{\left|Y_{t}-Y^{\prime}{ }_{t}\right|}{Y_{t}}
$$

data yang digunakan dalam penelitian ini adalah data primer yang didapatkan langsung dari XL Axiata cabang depok. Dan data yang digunakan adalah data primer dari bulan April 2015 s.d Maret 2016. Adapun contoh datanya seperti dibawah ini :

Tabel 2.1 Data contoh XL 5k

\begin{tabular}{|l|c|c|c|c|}
\hline No & Bulan & $\begin{array}{c}\text { Penjualan xl 5k } \\
\text { (Pcs) }\end{array}$ & $\begin{array}{c}\text { Persediaan xl 5k } \\
\text { (Pcs) }\end{array}$ & $\begin{array}{c}\text { Permintaan xl 5k } \\
\text { (Pcs) }\end{array}$ \\
\hline 1 & Apr-15 & 283.825 & 142.532 & 301.320 \\
\hline 2 & Mei-15 & 303.582 & 135.861 & 290.732 \\
\hline 3 & Jun-15 & 197.813 & 39.864 & 390.216 \\
\hline 4 & Jul-15 & 210.021 & 95.732 & 300.835 \\
\hline 5 & Agust-15 & 273.813 & 113.841 & 284.511 \\
\hline
\end{tabular}

Tabel 2.2 Data contoh XL 10k

\begin{tabular}{|c|c|c|c|c|}
\hline No & Bulan & $\begin{array}{c}\text { Penjualan xl 10k } \\
\text { (Pcs) }\end{array}$ & $\begin{array}{c}\text { Persediaan xl 10k } \\
\text { (Pcs) }\end{array}$ & $\begin{array}{c}\text { Permintaan xl 10k } \\
\text { (Pcs) }\end{array}$ \\
\hline 1 & Apr-15 & 555.787 & 58.176 & 591.000 \\
\hline 2 & Mei-15 & 517.836 & 115.213 & 592.833 \\
\hline 3 & Jun-15 & 583.611 & 127.968 & 510.582 \\
\hline 4 & Jul-15 & 596.934 & 153.210 & 565.814 \\
\hline 5 & Agust-15 & 510.930 & 182.100 & 519.833 \\
\hline
\end{tabular}

Tabel 2.3 Data contoh XL Rupiah

\begin{tabular}{|c|c|c|c|c|}
\hline No & Bulan & $\begin{array}{c}\text { Penjualan xl Rupiah } \\
\text { (Rupiah) }\end{array}$ & $\begin{array}{c}\text { Persediaan xl } \\
\text { Rupiah (Rupiah) }\end{array}$ & $\begin{array}{c}\text { Permintaan xI Rupiah } \\
\text { (Rupiah) }\end{array}$ \\
\hline 1 & Apr-15 & 6.982 .000 .000 & 982.712 .000 & 7.235 .000 .000 \\
\hline 2 & Mei-15 & 5.670 .300 .000 & 952.137 .000 & 5.874 .000 .000 \\
\hline 3 & Jun-15 & 5.353 .250 .000 & 983.260 .000 & 5.581 .000 .000 \\
\hline 4 & Jul-15 & 6.884 .700 .000 & 845.172 .000 & 7.135 .000 .000 \\
\hline 5 & Agust-15 & 5.391 .200 .000 & 635.813 .000 & 5.963 .000 .000 \\
\hline
\end{tabular}

\section{HASIL DAN PEMBAHASAN}

Didalam bab ini dimuat beberapa tahapan untuk mengolah data yang ada untuk mendapatkan hasil. Adapun tahapan yang dikerjakan adalah sebagai berikut :

a. Proses Fuzzy Inference System (FIS)

Pengolahan data awal dilakukan dengan cara membentuk variable penjualan, persedian dan permintaan kedalam bahasa lingustik dan menentukan semesta pembicaraan diteruskan dengan membuat fungsi keanggotaan dari masing masing variable permintaan, penjualan dan persediaan . pada proses ini dibentuk masing masing variable kedalam himpunan fuzzy, kemudian ditentukan masing masing semesta pembicaraan dan batas himpunannya.

Tabel 3.1 Variable dan semesta pebicaraan dompul 5k

\begin{tabular}{|l|l|c|l|}
\hline Fungsi & Variabel & $\begin{array}{c}\text { Semesta } \\
\text { Pembicaraan }\end{array}$ & Keterangan \\
\hline Input & Penjualan & {$[0-400]$} & $\begin{array}{l}\text { Jumlah } \\
\text { penjualan } \\
\text { dompul } \\
\text { perbulan } \\
\text { Ribu Pcs) }\end{array}$ \\
\hline Input & Persediaan & {$[0-200]$} & $\begin{array}{l}\text { Jumlah } \\
\text { Persediaan }\end{array}$ \\
\hline
\end{tabular}




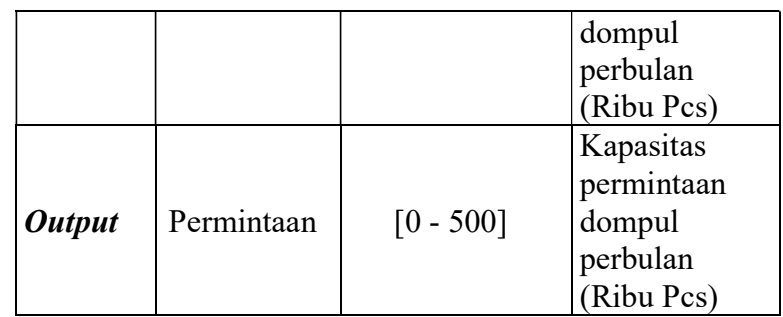

Tabel 3.2 Table himpunan fuzzy $5 \mathrm{k}$

\begin{tabular}{|c|c|c|c|c|}
\hline Fungsi & Variabel & $\begin{array}{c}\text { Nama } \\
\text { Himpunan } \\
\text { fuzzy }\end{array}$ & $\begin{array}{c}\text { Semesta } \\
\text { Pembicaraan } \\
\text { (Ribu pcs) }\end{array}$ & $\begin{array}{c}\text { Domain } \\
\text { (Ribu pes) }\end{array}$ \\
\hline \multirow{6}{*}{ Input } & \multirow{3}{*}{ Penjualan } & Turun & \multirow{3}{*}[0-400]{} & {$[0-200]$} \\
\hline & & Sedang & & {$[100-300]$} \\
\hline & & Naik & & {$[200-400]$} \\
\hline & \multirow{3}{*}{ Persediaan } & Sedikit & \multirow{3}{*}[0-200]{} & {$[0-100]$} \\
\hline & & Sedang & & {$[50-150]$} \\
\hline & & Banyak & & {$[100-200]$} \\
\hline \multirow{3}{*}{ Output } & \multirow{3}{*}{ Permintaan } & Sedikit & \multirow{3}{*}[0-500]{} & {$[0-250]$} \\
\hline & & Sedang & & {$[125-375]$} \\
\hline & & Banyak & & {$[250-500]$} \\
\hline
\end{tabular}

Tabel 3.3 Variable dan semesta pebicaraan dompul 10k

\begin{tabular}{|l|c|c|l|}
\hline Fungsi & Variabel & $\begin{array}{c}\text { Semesta } \\
\text { Pembicaraan }\end{array}$ & Keterangan \\
\hline Input & Penjualan & {$[0-700]$} & $\begin{array}{l}\text { Jumlah } \\
\text { penjualan } \\
\text { dompul } \\
\text { perbulan } \\
\text { (Ribu Pcs) }\end{array}$ \\
\hline Input & Persediaan & {$[0-200]$} & $\begin{array}{l}\text { Jumlah } \\
\text { Persediaan } \\
\text { dompul } \\
\text { perbulan } \\
\text { (Ribu Pcs) }\end{array}$ \\
\hline Output & Permintaan & {$[0-700]$} & $\begin{array}{l}\text { Kapasitas } \\
\text { permintaan } \\
\text { dompul } \\
\text { perbulan } \\
\text { (Ribu Pcs) }\end{array}$ \\
\hline
\end{tabular}

Tabel 3.4 Table himpunan fuzzy 10k

\begin{tabular}{|c|c|c|c|c|}
\hline Fungsi & Variabel & $\begin{array}{c}\text { Nama } \\
\text { Himpunan } \\
\text { fuzzy }\end{array}$ & $\begin{array}{c}\text { Semesta } \\
\text { Pembicaraan } \\
\text { (Ribu pcs) }\end{array}$ & $\begin{array}{l}\text { Domain } \\
\text { (Ribu pes) }\end{array}$ \\
\hline \multirow{6}{*}{ Input } & \multirow{3}{*}{ Penjualan } & Turun & \multirow{3}{*}[0-700]{} & {$[0-350]$} \\
\hline & & Sedang & & {$[175-525]$} \\
\hline & & Naik & & {$[350-700]$} \\
\hline & \multirow{3}{*}{ Persediaan } & Sedikit & \multirow{3}{*}[0-200]{} & {$[0-100]$} \\
\hline & & Sedang & & {$[50-150]$} \\
\hline & & Banyak & & {$[100-200]$} \\
\hline \multirow{3}{*}{ Output } & \multirow{3}{*}{ Permintaan } & Sedikit & \multirow{3}{*}[0-700]{} & {$[0-350]$} \\
\hline & & Sedang & & {$[175-525]$} \\
\hline & & Banyak & & {$[350-700]$} \\
\hline
\end{tabular}

Tabel 3.5 Variable dan semesta pebicaraan dompul rupiah

\begin{tabular}{|l|c|c|l|}
\hline Fungsi & Variabel & $\begin{array}{c}\text { Semesta } \\
\text { Pembicaraan }\end{array}$ & Keterangan \\
\hline \multirow{2}{*}{ Input } & Penjualan & {$[0-10]$} & $\begin{array}{l}\text { Jumlah } \\
\text { penjualan } \\
\text { dompul } \\
\text { perbulan } \\
\text { (Milyar } \\
\text { Rupiah) }\end{array}$ \\
\cline { 2 - 4 } & Persediaan & {$[0-2]$} & $\begin{array}{l}\text { Jumlah } \\
\text { Persediaan } \\
\text { dompul } \\
\text { perbulan } \\
\text { (Milyar } \\
\text { Rupiah) }\end{array}$ \\
\hline \multirow{2}{*}{ Output } & Permintaan & {$[0-12]$} & $\begin{array}{l}\text { Kapasitas } \\
\text { permintaan } \\
\text { dompul } \\
\text { perbulan } \\
\text { (Milyar } \\
\text { Rupiah) }\end{array}$ \\
\hline
\end{tabular}

Tabel 3.6 Table himpunan Fuzzy rupiah

\begin{tabular}{|c|c|c|c|c|}
\hline Fungsi & Variabel & $\begin{array}{c}\text { Nama } \\
\text { Himpun } \\
\text { an fuzzy }\end{array}$ & $\begin{array}{c}\text { Semesta } \\
\text { Pembicaraan } \\
\text { (Milyar } \\
\text { Rupiah) } \\
\end{array}$ & $\begin{array}{l}\text { Domain } \\
\text { (Milyar } \\
\text { Rupiah) }\end{array}$ \\
\hline \multirow{6}{*}{ Input } & \multirow{3}{*}{ Penjualan } & Turun & \multirow{3}{*}{ [0 - 10] } & {$[0-5]$} \\
\hline & & Sedang & & {$[2,5-7,5]$} \\
\hline & & Naik & & {$[5-10]$} \\
\hline & \multirow{3}{*}{$\begin{array}{l}\text { Persediaa } \\
\mathrm{n}\end{array}$} & Sedikit & \multirow{3}{*}[0-2]{} & {$[0-1]$} \\
\hline & & Sedang & & {$[0,5-1,5]$} \\
\hline & & Banyak & & {$[1-2]$} \\
\hline \multirow[b]{3}{*}{ Output } & \multirow{3}{*}{$\begin{array}{l}\text { Perminta } \\
\text { an }\end{array}$} & Sedikit & \multirow[b]{3}{*}[0-12]{} & {$[0-6]$} \\
\hline & & Sedang & & {$[3-9]$} \\
\hline & & $\begin{array}{l}\text { Banya } \\
\mathrm{k}\end{array}$ & & {$[6-12]$} \\
\hline
\end{tabular}

b. Aturan Fuzzy Inference System (FIS)

Tahapan selanjutnya dari proses Fuzzy Inference System ini adalah menentukan aturan yang berlaku. Pada tahapan ini dibentuk aturan aturan yang mengatur bagaimana Fuzzy Inference System ini bekerja. Aturan ini dibentuk berdasarkan aturan yang diterapkan diperusahaan dan diterapkan kedalam aturan fuzzy inference system (FIS).

Adapun aturan yang telah dibuat dapat dilihat didalam table dibawah ini : 
Aturan Fuzzy Inference System

\begin{tabular}{|l|l|l|l|}
\hline \multirow{2}{*}{ No } & \multicolumn{3}{|c|}{ Variabel } \\
\cline { 2 - 4 } & Penjualan & Persediaan & Permintaan \\
\hline $\mathbf{1}$ & Turun & Sedikit & Sedikit \\
\hline $\mathbf{2}$ & Turun & Sedang & Sedikit \\
\hline $\mathbf{3}$ & Turun & Banyak & Sedikit \\
\hline $\mathbf{4}$ & Sedang & Sedikit & Sedang \\
\hline $\mathbf{5}$ & Sedang & Sedang & Sedang \\
\hline $\mathbf{6}$ & Sedang & Banyak & Sedang \\
\hline $\mathbf{7}$ & Naik & Sedikit & Banyak \\
\hline $\mathbf{8}$ & Naik & Sedang & Banyak \\
\hline $\mathbf{9}$ & Naik & Banyak & Banyak \\
\hline
\end{tabular}

c. Defuzzifikasi

Langkah selanjutnya adalah defuzzifikasi. Pada tahap ini biasanya langkah terakhir dalam suatu sistem logika fuzzy dimana tujuannya adalah mengkonversi setiap hasil dari inference engine yang diekspresikan dalam bentuk fuzzy set kesuatu bilangan real. Hasil konversi tersebut merupakan aksi yang diambil oleh sistem kendali logika fuzzy.

Misal digunakan sebagai data uji adalah data XL 5k bulan Maret 2016 dengan Penjualan sebanyak 356,790 Ribu Pcs dan data pembelian sebanyak 55,174 Ribu Pcs maka data permintaan sebagai berikut :

Data penjualan 356,790

$$
\begin{gathered}
\mu \operatorname{Naik}(x)=\left\{\begin{array}{ll}
0 ; & x \leq 200 \\
\frac{x-200}{200} ; & 200 \leq x \leq 400 \\
1 ; & x \geq 400
\end{array}\right\} \\
\mu \operatorname{Naik}(x)=\frac{356,790-200}{200}=0.78
\end{gathered}
$$

Data persediaan 55,174

$$
\begin{aligned}
& \mu \operatorname{Sedikit}(x)=\left\{\begin{array}{cc}
\frac{100-x}{100} ; & 0 \leq x \leq 100 \\
0 ; & x \geq 100
\end{array}\right\} \\
& \mu \operatorname{Sedikit}(x)=\frac{100-55,174}{100}=0.45
\end{aligned}
$$

$$
\begin{aligned}
& \mu \text { Sedang }(x) \\
& =\left\{\begin{array}{ll}
0 ; & x \leq 50 \text { atau } x \geq 150 \\
\frac{x-50}{50} ; & 50 \leq x \leq 100 \\
\frac{150-x}{50} ; & 100 \leq x \leq 150
\end{array}\right\}
\end{aligned}
$$

$\mu \operatorname{Sedang}(x)=\frac{55,174-50}{50}=0.10$

Dengan menggunakan aplikasi fungsi implikasi didapat nilai sebagai berikut :

1. Jika Penjualan Naik And Persediaan Sedikit Then Permintaan Banyak

2. Jika Penjualan Naik And Persediaan Sedang Then Permintaan Banyak

Aplikasi Fungsi Implikasi :

1) Jika Penjualan Naik Dan Persedian Sedikit, MAKA Permintaan Banyak $\alpha$ predikat $1=\mu$ pnjNaik $\cap \mu$ psdSedikit $=$

$\min (\mu p n j N a i k(356,790) ; \mu p s d S e d i k i t(55,174))$ $=\min (0.78 ; 0.45)=0.45$

2) Jika Penjualan Naik Dan Persedian Sedang, MAKA Permintaan Banyak $\alpha$ predikat $1=\mu$ pnjNaik $\cap \mu$ psdSedang $=$

$\min (\mu \mathrm{pnjNaik}(356,790) ; \mu$ psdSedang $(55,174))$ $=\min (0.78 ; 0.10)=0.10$

Dengan metode centroid :

$$
z^{*}=\frac{\int_{z} z \mu(z) d z}{\int_{z} \mu(z) d z}
$$

Titik pusat dapat diperoleh dari:

$$
\begin{array}{r}
\frac{17075.625+21147.505+26683.60}{123.75+24,06+13.75} \\
=\frac{64906.73}{161.56}=401.750
\end{array}
$$

Kesimpulan, Jika Penjualan 333,790 Ribu Pcs dan Persediaan 55,174 Ribu Pcs maka Jumlah Permintaan adalah 401.750 Ribu Pcs.Untuk menentukan jumlah permintaan pada bulan Maret 2016, dapat dilihat pada tabel dibawah ini:

Tabel 3. 1 Hasil Uji Sampel Metode Mamdani

\begin{tabular}{|c|l|c|c|c|}
\hline No & DATA & Persediaan & Penjualan & Pembelian \\
\hline 1 & XL 5k & 356,790 & 55,147 & 402 \\
\hline 2 & XL 10k & 573,977 & 114,021 & 574 \\
\hline 3 & XL Rupiah & 7,21 & 0,995 & 8,9 \\
\hline
\end{tabular}

Dari penelitian yang sudah dilakukan maka didapat hasil perbandingan penilaian Logika Fuzzy (Mamdani) dengan menggunakan persentase rata - rata atau Mean Absolute Percentage Error (MAPE) dengan rumus: 
MAPE $=\frac{1}{n} \sum_{t=1}^{n} \frac{\left|Y_{t}-Y^{\prime}{ }_{t}\right|}{Y_{t}}$

Keterangan:

$M A P E=$ Mean Absolute Percentage Error

$Y_{t}=$ Nilai data time series pada periode $t$

$Y^{\prime}{ }_{t}=$ Nilai ramalan dari $Y_{t}$

Dari nilai uji tersebut didapatkan nilai MAPE sebagi berikut :

1. Mape untuk data XL 5k adalah

$M A P E=\frac{1}{n} \sum_{t=1}^{n} \frac{\left|Y_{t}-Y^{\prime}{ }_{t}\right|}{Y_{t}}=\frac{2,225712}{12} \times 100 \%$

$$
=18,56 \%
$$

2. Mape untuk XL 10k adalah

MAPE $=\frac{1}{n} \sum_{t=1}^{n} \frac{\left|Y_{t}-Y^{\prime}{ }_{t}\right|}{Y_{t}}=\frac{0,645507}{12} \times 100 \%$ $=5,38 \%$

3. Mape untuk XL Rupiah adalah

MAPE $=\frac{1}{n} \sum_{t=1}^{n} \frac{\left|Y_{t}-Y^{\prime}{ }_{t}\right|}{Y_{t}}=\frac{1,778853}{12} \times 100 \%$
$=14,82 \%$

Setelah semua data diolah dan dihitung menggunakan Fuzzy Inference System (FIS) metode mamdani dan digunakan Mean Absolute Precentage Error (MAPE) sebagai bahan validasi maka dapat disajikan data perbandingan perhitungan yang dilakukan oleh manajemen dan perhitungan Fuzzy Inference System (FIS) didalam grafik dibawah ini:

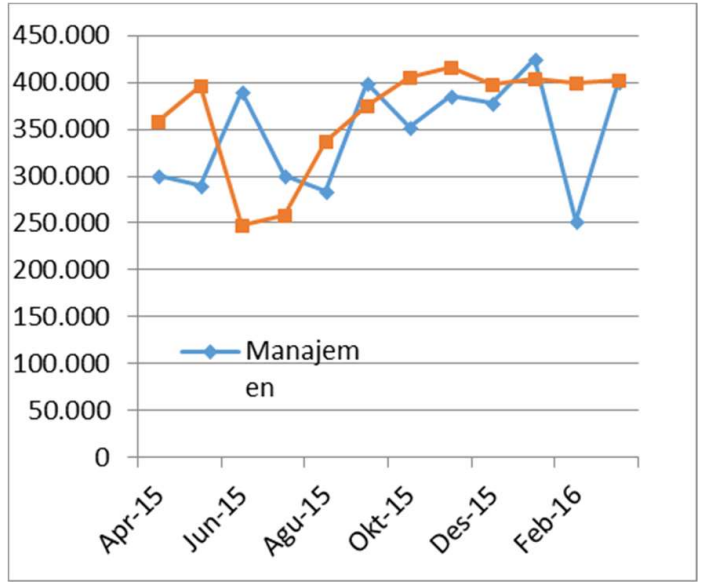

Gambar 3.2 Grafik Permintaan Manjemen dan FIS Mamdani

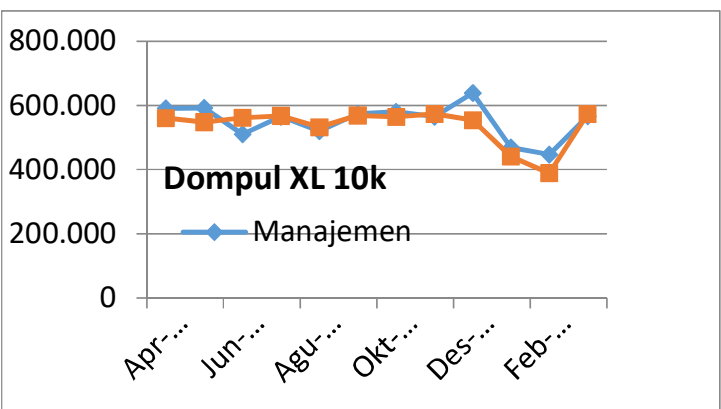

Gambar 3.2 Grafik Permintaan Manjemen dan FIS Mamdani

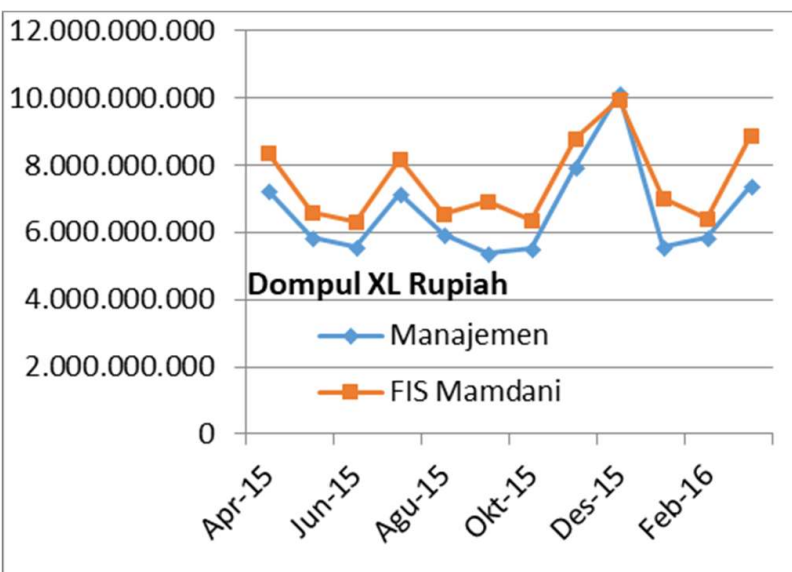

Gambar 3.3 Grafik Permintaan Manjemen dan FIS Mamdani

Dilihat dari hasil perbandingan tersebut membuktikan bahwa prediksi permintaan dompet pulsa yang dilakukan dengan Fuzzy inference system metode mamdani dapat membuat permintaan dompet pulsa jauh lebih efisien, tidak terlalu banyak ataupun tidak terlalu sedikit, melihat dari 12 sampel data yang telah diuji sebagai bahan acuan kelayakan penggunaaan metode.

\section{KESIMPULAN}

Berdasarkan rumusan masalah, hasil penelitian dan pembahasan mengenai penentuan jumlah pembelian produk berdasarkan data persediaan dan penjualan dapat diambil beberapa kesimpulan, yaitu:

1. Logika fuzzy (Mamdani) dalam menentukan jumlah permintaan dompet pulsa yang telah dibangun dapat digunakan untuk membantu perusahaan dalam mengambil sebuah keputusan dengan nilai $M A P E 18,56 \%$ untuk Dompul XL 5k, 5,38\% untuk Dompul XL 10k dan 14,2\% untuk Dompul XL Rupiah. 
2. Logika fuzzy (mamdani) yang telah dimodelkan dalam sistem prediksi dompet pulsa ini dapat membantu perusahaan untuk menetukan permintaan dibulan berikutnya.

\section{REFERENSI}

Kusumadewi. S , H. P. (2013). Aplikasi Logika Fuzzy Untuk Pendukung Keputusan. Graha Ilmu. Yogyakarta.

Heizer, Jay \& Render, B. 2015. Operations Management (Manajemen Operasi). Edisi 11. Penerjemah: Dwi anoegrah wati $\mathrm{S}$ dan Indra Almahdy. Salemba empat. Jakarta.

Widodo, P. P. 2012. Penerapan Soft Computing dengan Matlab. Rekayasa Sains. Bandung. 